University of Nebraska - Lincoln

DigitalCommons@University of Nebraska - Lincoln

Sociology Department, Faculty Publications

Sociology, Department of

2020

Law and Same-Sex Couples' Experiences of Childbirth

Emily Kazyak

Emma Finken

Follow this and additional works at: https://digitalcommons.unl.edu/sociologyfacpub

Part of the Family, Life Course, and Society Commons, and the Social Psychology and Interaction Commons

This Article is brought to you for free and open access by the Sociology, Department of at DigitalCommons@University of Nebraska - Lincoln. It has been accepted for inclusion in Sociology Department, Faculty Publications by an authorized administrator of DigitalCommons@University of Nebraska - Lincoln. 


\title{
Law and Same-Sex Couples' Experiences of Childbirth
}

\author{
Emily Kazyak and Emma Finken
}

University of Nebraska-Lincoln

In 2017, the Supreme Court ruled in Pavan v. Smith that states must allow married same-sex couples to both be listed as parents on their child's birth certificate. Although the ruling garnered less media attention than the Court's 2015 Obergefell v. Hodges decision on marriage, it nonetheless illustrates a significant issue pertinent to the families who are the focus of this chapter: lesbian same-sex couples who had children via donor insemination before 2015. Indeed, prior to this ruling, these couples faced an unequal legal climate insofar as only the biological mother could be listed on the birth certificate and thus be legally recognized as a parent; the nonbiological mother had no legal recognition of her parenthood. Couples often pursued a second-parent adoption so that the nonbiological mother could be legally recognized as a parent. Yet this option was not available to all couples; state laws allowed, denied, or made uncertain same-sex couples' access to pursuing this legal recognition for the nonbiological mother (Dalton 2001; Kazyak 2015). Drawing on data from interviews with twentyone lesbian parents, we analyze how the unequal and varied legal context shapes their health care experiences related to childbirth.

\footnotetext{
Published as Chapter 12 in Marriage and Health: The Well-Being of Same-Sex Couples, edited by Hui Liu, Corinne Reczek, \& Lindsey Wilkinson (New Brunswick: Rutgers University Press, 2020), pp 176-187. Copyright (c) 2020 Emily Kazyak \& Emma Finken.
} 
Our analysis is informed by social science research that focuses on "the relevance of law in everyday life" (Erlanger 2005). We follow in what Richman (2009) defines as the "constitutive" theoretical tradition that seeks to understand the mutually constitutive relationship between laws on the books and how law is imagined and experienced in daily life. This theoretical perspective focuses on "everyday people's" engagement with the law and legal categories and argues that the law serves as an interpretive framework through which people understand themselves and others in everyday life (Ewick and Silbey 1998). People may embrace, reject, or rework legal categories in social interactions (Baumle and Compton 2015). Guided by this constitutive theoretical framework in sociolegal studies, in our chapter, we ask: how is the law present in lesbian women's health care experiences? We focus on pregnancy, childbirth, and postpartum health care.

We draw on data from interviews with both biological and nonbiological mothers in three states with different second-parent adoption laws (Nebraska/ unavailable, Iowa/guaranteed, Missouri/uncertain). We address how the legal variation (i.e., the nonbiological mother could do a second-parent adoption in some but not all states represented in the sample) mattered to their decision-making processes related to health care. Namely, we find that those living in states with unavailable or uncertain access discussed the option of giving birth in a different state that had guaranteed access.

We also address how the legal inequity faced by all of the couples (i.e., the nonbiological mother was not immediately legally recognized as a parent in any state) mattered to their health care experiences. We find that this lack of legal equity permeated how lesbian women expected to be treated within health care settings. All couples, regardless of state, experienced fear that they would be discriminated against as a result of their sexual orientation and that this would be worse for the nonbiological mother especially, given her lack of legal rights. Our analysis illustrates that the decisions LGBTQ people make about their health care and their experiences within health care settings are embedded in a broader legal context. Additionally, our analysis highlights the role that health care providers may play in alleviating LGBTQ people's apprehension about health care settings. 


\section{Methods}

\section{Data Collection and Analysis}

Data come from twenty-one interviews with lesbian parents. All interviewees had a child within the context of a same-sex' couple using donor insemination and both biological mothers and nonbiological mothers were interviewed. The interviews were conducted in 20122013 by the first author as part of a larger project about how lesbian couples experience, understand, and make decisions about second-parent adoption. Participants were recruited from three states that had different laws regarding second-parent adoption for same-sex couples at the time the interviews were conducted: Iowa (guaranteed access), Missouri (uncertain access), and Nebraska (unavailable access). Participants were recruited through a purposive, convenience sample with several starting points so as not to over-rely on particular social networks. Starting points included regional LGBTQ organizations in each state (such as PFLAG) as well as churches with welcoming LGBTQ-friendly stances. The first author also recruited through national LGBTQ organizations (such as Equality Resource Council and LGBTQ parenting groups on websites such as Babycenter.com) and through a public Facebook page.

The first author conducted all of the interviews in-person, over the phone, or over Skype. Prior to the interview, people completed a short survey that included demographic questions. The survey also included questions about their relationship with their child and their experiences with the law (e.g., whether they were recognized as a legal parent). The interviews were semistructured and covered questions about how they gained information about the legal climate in which they were living, their decision-making process about whether or not to do a second-parent adoption, and their experiences regarding the law in both interpersonal and institutional interactions.

Once the data were collected, the interviews were transcribed in full and coded using QSR-Nvivo software. The first author began analyses by reading through the transcripts and taking notes on interesting emerging themes, what Emerson, Fretz, and Shaw (1995) refer to as "open coding." During this process, the first author was struck by how salient the law was in people's narratives about their pregnancy, 
labor and delivery, and postpartum care. After doing open coding and generating themes, the first author trained two graduate student research assistants to code the interviews using them. After the interview data were coded, the first author wrote analytic memos that linked themes, which were developed into the findings in the following text in collaboration between the authors. The memos allowed us to assess whether variation among the participants existed with regard to each topic (e.g., were people in states with guaranteed access less likely to talk about the law?). In order to ensure confidentiality, pseudonyms are used. The quotes were edited for the sake of both confidentiality and clarity, but the meaning and words have not been otherwise changed.

\section{Profile of Participants}

The sample includes participants from each state in roughly equal proportions (see Table 1). Respondents were diverse in terms of whether they lived in urban, rural, or suburban areas, as well as their class status, but less so with regard to race and ethnicity, as the sample is predominately white (see Kazyak 2015 for more discussion of demographics of the sample). In all but one family, one parent was biologically related and one parent was not biologically related to their children (in one family, each parent had given birth). With regard to legal status, half of the sample (10 participants) pursued a second-parent adoption and half (II participants) did not pursue a second-parent adoption (but one participant was in the process). Those who did a second-parent adoption include two couples who were living in $\mathrm{Ne}$ braska but did a second-parent adoption in another state. Six people in the sample do not have a legal tie to their child(ren).

\section{Results}

\section{Health Care Decision-Making Processes: Deciding Where to Give Birth}

In this section we discuss how the state legal context influenced women's health care decisions about where to give to birth. The availabil-

ity of second-parent adoptions differed across states at the time of 
Table 1 Interviewee Demographics

\begin{tabular}{|c|c|c|c|c|}
\hline Pseudonym & State & Bio-mom? & $\begin{array}{l}\text { Legally recognized } \\
\text { as parent? }\end{array}$ & $\begin{array}{l}\text { State law } \\
\text { second-parent } \\
\text { adoption }\end{array}$ \\
\hline Anne & Nebraska & No & No Unavailable & \\
\hline Barbara & Nebraska & No & $\begin{array}{l}\text { Yes, through 2nd } \\
\text { parent adoption }\end{array}$ & Unavailable \\
\hline Tiffany & Nebraska & Yes & Yes, since birth & Unavailable \\
\hline Victoria & Missouri & Yes & Yes, since birth & Uncertain \\
\hline Grace & Missouri & No & No Uncertain & \\
\hline Cathy & Missouri & No & $\begin{array}{l}\text { Yes, through 2nd } \\
\text { parent adoption }\end{array}$ & Uncertain \\
\hline Harriet & Missouri & Yes & Yes, since birth & Uncertain \\
\hline Darcie & Iowa & No & $\begin{array}{l}\text { Yes, through 2nd } \\
\text { parent adoption }\end{array}$ & Guaranteed \\
\hline Linda & Iowa & Yes & Yes, since birth & Guaranteed \\
\hline Elizabeth & Iowa & No & No & Guaranteed \\
\hline Melanie & Missouri & Yes & Yes, since birth & Uncertain \\
\hline Jan & Nebraska & Mix & $\begin{array}{l}\text { Yes, since birth } \\
\text { and through 2nd } \\
\text { parent adoption }\end{array}$ & Unavailable \\
\hline Tanya & Nebraska & Mix & $\begin{array}{l}\text { Yes, since birth } \\
\text { and through 2nd } \\
\text { parent adoption }\end{array}$ & Unavailable \\
\hline Shawna & Missouri & Yes & Yes, since birth & Uncertain \\
\hline Joyce & Missouri & No & No & Uncertain \\
\hline Pamela & Iowa & Yes & Yes, since birth & Guaranteed \\
\hline Robyn & Iowa & No & $\begin{array}{l}\text { Yes, through 2nd } \\
\text { parent adoption }\end{array}$ & Guaranteed \\
\hline Erin & Nebraska & Yes & Yes, since birth & Unavailable \\
\hline Phoebe & Nebraska & No & No & Unavailable \\
\hline Ellen & Nebraska & Yes & Yes, since birth & Unavailable \\
\hline Nikki & Nebraska & No & No & Unavailable \\
\hline
\end{tabular}

the study, and this variation influenced lesbian women's experiences. Specifically, for the women residing in Nebraska and Missouri, states where second-parent adoption was either unavailable or contingent on county within the state, respectively, the law was quite salient in their decision-making process about where to give birth. No one in Iowa discussed the legal context as part of their decision-making process about where to give birth. 
Consider the experiences of Cathy and Harriet who live in Missouri, a state with, as they put it, "confusing" and "ambiguous" laws. When describing where they gave birth, Cathy said: "We were told that as long as you deliver in the county as opposed to the city, you can apply for second-parent adoption, but you can't do that in the city." Since the laws in the county "didn't coincide" with the laws in the city where they lived, Cathy explained, "we delivered in the county to be able to do the adoption."

Other couples who lived in Missouri and also Nebraska couples had contemplated driving to Iowa, a state with guaranteed access to second-parent adoption for same-sex couples. Victoria who lived in Missouri commented: "We've talked about driving over [state] lines into Iowa for her to have this baby." The possibility of giving birth in Iowa also emerged in the interview with Ellen and Nikki, a couple living in Nebraska. As Ellen discussed their decision to give birth in Nebraska instead of Iowa, she stated: "I feel like if we lived closer to the border it would have been one thing to just like hop over to Iowa to the hospital, "Since they did not live close to Iowa's border, they ultimately decided to not "go through all that" and Ellen gave birth in Nebraska.

Although the law did not ultimately influence where Ellen and Nikki or Victoria and Grace ultimately gave birth, the fact that it was part of their decision-making process illuminates how lesbian women weigh their options with a consideration of a broader legal context. Such references to the law and availability of second-parent adoption did not emerge in the narratives of lesbian women living in Iowa. Since these couples were guaranteed access to second-parent adoption regardless of where in the state they delivered their child, they did not have to consider different hospitals in different parts of the state or a different state entirely as they decided where to give birth.

\section{Expectations for Treatment in Health Care Settings}

In this section, we focus on the expectations that women had about how they would be treated in health care settings. We find that overall women's expectations were quite low insofar as they articulated fears that they would be discriminated against and concerns that their family's lack of legal equity would translate into poor treatment by 
health care providers. The narratives of fear and concern were consistent in interviewees across states. We argue the lack of variation across states reflects the fact that even in states that guarantee access to second-parent adoption, these families nonetheless faced the scenario where the nonbiological mother would not have legal ties to her child until that second-parent adoption took place. Thus, all couples experienced the pregnancy and labor and delivery and postpartum care without that legal protection. We divide this section into two parts. First, we discuss how lesbian women were fearful about how the nonbiological mom would be treated within health care settings. Of course, a sense of fear and anxiety when approaching childbirth is not necessarily unique to lesbian women (Melender 2002). However, these couples had additional worries that stemmed from the lack of legal equity. We highlight how their expectations for health care settings were so fraught with fear by noting how each family thought about "worse case hypothetical scenarios" they might encounter. Second, we discuss the strategies that lesbian women used to try to mitigate their fear, which further illustrates the degree to which the lack of legal equity for their family (and especially for the nonbiological mom) factored into their expectations for how they would be treated in health care settings.

\section{Fear for Nonbiological Mom and Worst-Case Hypothetical Scenarios}

Participants discussed having a lot of fear about how the nonbiological mother would be treated during labor and delivery. For example, Cathy said: "My biggest fear would be somebody [in the hospital] telling me I couldn't go somewhere or see my son or see my wife." Joyce also recalled a sense of anxiety as the nonbiological mother. Among the things she was nervous about included "Are you going to let me into the delivery room? If she has a $\mathrm{C}$-section, are you going to let me in there? Will I be able to go down and hold my baby? Am I going to be the one who's allowed to have that bracelet, allowing me to you know go get my baby from the nursery if I want to?” Explicitly explaining how her fears were rooted in the law, Joyce noted: "My worse fear was ... I'll want to go get my baby, I'll have no rights to [my son] and they won't let me see him.” The lack of legal equity Joyce experienced 
translated into medical situations being "terrifying for me on my end not being the biological parent." The questions, concerns, and fear raised by Cathy and Joyce echoed those that other nonbiological moms raised. As Joyce's quote illustrates, their fear for how they would be treated stemmed from the fact that they knew they were not legally recognized as a parent, and thus they were unsure if they would have access to certain things (e.g., having a bracelet that would allow them to go to the nursery to hold their baby).

The fear that permeated people's expectations for how the nonbiological mother would be treated in health care settings is also illustrated what we call "worst case hypothetical scenarios." These were scenarios they had imagined that typically involved either the biological mother or the child dying. As couples entertained these scenarios, they expressed fear about whether the nonbiological mother would either be able to retain custody of their child or be able to be with her spouse. Again, these fears stemmed from the lack of legal equity these families experienced insofar as the nonbiological mom would be considered a legal stranger.

In discussing her thinking through of the worst-case scenario of her wife dying in childbirth, Victoria mused: "Would they just let me keep the baby?" She had even considered whether she needed to become a foster parent so she could immediately petition to keep the baby in the event of such a situation. This concern that the nonbiological parent would not be able to retain custody of their child in the event of the biological parent's death was echoed by every interviewee. People also discussed the fear of not being able to make medical decisions for their child if this worst-case scenario occurred. Linda described the fear from the perspective of being the biological-related mother, saying: "What if something happened to me, who would speak for the child?" Her wife echoed the concern that "I might not have access to my child's medical records, because I don't have a legal relationship with him." In sum, the lack of legal protection for the nonbiological mom that families in all states experienced translated into families thinking through worst-case scenarios and being fearful about treatment in health care settings. Next, we turn to the strategies families used to help mitigate those fears. 


\section{Strategies Used to Lessen Fears about Health Care Settings}

One strategy the lesbian women used was obtaining as much legal protection for the nonbiological mother as possible and bringing that documentation to the hospital. Examples include making living wills, making sure their relationship status was solidified and recognized, and having the nonbiological mother become a health proxy. Cathy combated her anxieties about her legal status using several of these methods: "[Wife] did a living will. And there was another [health] proxy, so that I can make decisions for her and so that everything would be deferred to me personally. She ... printed off generic documents from [the insurance providers] and we both signed them and had them notarized and turned them in to our doctors and the hospital where we delivered so everything was scanned in and in our charts." others also took protective measures for the nonbiological mother: Harriet said "[the hospital staff] asked for both our proxy and living will. So we gave it to them and they put it in the file." Likewise, Erin and Phoebe detailed the various measures they had taken to ensure that the nonbiological mother had as many legal protections as she could. They explained: "We carry a pin on us at all times" that contains electronic copies of documents like a power of attorney. Phoebe explained they carry it at all times "because if anything were to happen and we are at the hospital and she can't answer for herself or [their son] then I just show them the papers.” All of these examples illustrate the degree to which the law permeated lesbian women's expectations for how their families and the nonbiological mother in particular would be treated in health care settings.

A second strategy used by couples that had done a second-parent adoption was to make sure health care providers were aware that the nonbiological mother was legally recognized as a parent and thus had the legal ability to make medical decisions for her child. For instance, Jan and Tanya were the one couple living in Nebraska who had done a second-parent adoption in another state. Jan, the nonbiological mother, explained that when they moved, she was very clear with their new pediatrician that she is the "adoptive mother." In explaining why she "made a point to say I'm the adoptive mother," she said that she "wanted to convey to them I have legal standing here [and let them know that] I can make legal decisions for this child, so 
don't bother to question me." This strategy further illustrates the fear that without health care providers having that awareness, the nonbiological mother may be denied treatment decisions. Next, we discuss whether their expectations were realized as we detail their actual experiences within health care settings.

\section{Experiences in Health Care Settings}

In general, the fears that lesbian women had about how their family and how the nonbiological mother would be treated by health care providers were not often realized. As we outline, many reported overall positive interactions. We also do discuss, however, instances of negative interactions with health care providers.

\section{Positive Experiences}

Several women recalled their positive experiences at the hospital during pregnancy, labor and delivery, and other parenting-related health care services. Melanie noted: "I think the hospital was really amazing .... Everybody who came in, I introduced her as my wife [to them], that sort of thing, [so] I didn't. set it up where there would be any sort of issue.” Referencing her experience as a nonbiological mother, Darcie said: "I can't say that I've ever been treated as the lesser parent from doctors." Others mentioned experiences they had where they thought that health care providers made an extra effort to be inclusive and supportive. For instance, Harriet explained: “Our OB's office was really nice .... If anything we felt extra special. ... I felt like the nurses just loved us ... [because the nurses thought] what's better than one mom? Two." Phoebe also described an experience that was "really nice" and made her feel that the doctor's office "did a really good job" being supportive. She retold the experience of their first appointment when her spouse was eight weeks pregnant: "One nurse said, 'Oh, you're a support for someone? [and I replied] 'Yeah,' ... and the nurse was looking through the paperwork and she looked at me and said You're more than her support person, you're her wife, why didn't you say anything? That's awesome! Congratulations to you, too!'” Both of these stories speak to the positive impact that health care practitioners can have in terms of being inclusive and supportive of same-sex couples and LGBTQ people. 


\section{Negative Experiences}

Other couples experienced less supportive health care providers and settings. For instance, Victoria said that she has told the doctor's office "about a million times" that she and Grace were married, but they nonetheless "would enter her as my sister because we have the same last name." Jan also shared an experience at a pediatrician's office where the pediatrician informed her: "My nurse was kind of uncomfortable with your status, so I'm going to be handling this." Jan recalled being angry at both the nurse's reaction and at the doctor for telling her about the nurse's reaction and has since switched pediatricians.

Two additional stories illustrate how lesbian experiences within health care settings can be negative (even without a specific health care provider being unsupportive) due to the lack of legal equity their families faced. Erin and Phoebe described their experiences at a hospital where they had their child as positive overall, but did note "the only thing that was maybe not good ... they make you watch videos before they let us leave the hospital and one of them is talking about how you have to get married so you can have your rights as a father." Although their interactions with health care providers were positive, that the hospital promoted a video that ignored same-sex couples and highlighted their family's legal inequity (Le., they did not have the option to get married or have rights granted to the nonbiological parent) indicates how lesbian women can experience health care settings (not providers per se) as unsupportive.

Darcie and Linda described the experience of filling out their child's birth certificate application in the hospital as an extremely invalidating and emotionally charged experience. Darcie explained that having to only list the biological mother coupled with having to identify her as unmarried to avoid having to list a father "was much more emotional than we ever imagined" and in fact referred to it as "gut wrenching." Linda explained why it was so emotional: "Not only are we not acknowledging the nonbiological mother, we're not acknowledging your marriage either." Linda and Darcie said that even when the hospital staff person came in with the birth certificate application, they both "just bustled] out crying." Their story underscores how negative health care experiences that stem from legal inequity can occur even without anyone health care provider being discriminatory or unsupportive. 
In sum, people's stories indicate how medical providers can mitigate or compound stress that comes with an unequal legal landscape. Couples in all states reported both positive and negative interactions with health care providers.

\section{Discussion}

As LGBTQ people increasingly have children after coming out and/or in the context of a same-sex marriage, it is important to address their expectations and experiences surrounding parenting. Given that pregnancy and birth are medicalized processes (Simonds, Rothman, and Norman 2007), examining how lesbian same-sex couples experience childbirth sheds light on issues pertaining to health and same-sex couples. Our overarching goal in this chapter is to underscore that decisions related to health care and experiences with health care practitioners cannot adequately be understood without accounting for the legal context within which those decisions and experiences occur. In other words: legal inequity for LGBTQ people matters to their health care experiences. For lesbian couples having children via donor insemination, the lack of guaranteed legal recognition of the nonbiological mother permeated their expectations for health care settings. Their accounts underscore the feelings of fear and anxiety experienced when anticipating interacting with health care practitioners. Future work should address whether lesbian couples still approach health care with a sense of fear and anxiety given changes in laws. Since changes in the laws do not always translate evenly to changes in practices, questions remain, for instance, about whether the Supreme Court 2017 decision has affected how states process birth certificates. Moreover, newly passed religious freedom laws in some states that allow health care providers to be exempt from working with LGBTQ people may continue to negatively impact the experiences of lesbian couples (Kazyak, Burke, and Stange 2018; Miller 2018).

It is important to note that in most cases, people's fears were not actually realized. By and large lesbian women in our study reported overall positive interactions with health care providers. Yet the fact that these positive experiences stood out to them, not to mention their discussions of what they anticipated, helps to highlight that they did 
not start with the expectation of inclusive and supportive health care treatment. Our work indicates that it is important to recognize the role that health care providers might play in mitigating the stress and fear that lesbian women experience. The law and legal categories were central to how lesbian women approached health care settings. Yet for some health care providers, the law and legal categories were seemingly not important to how they interacted with and treated samesex couples (Le., they recognized the nonbiological mother as a parent during labor even though she was consider a "legal stranger" by law). These accounts illustrate how people may reject legal categories in social interactions (Ewick and Silbey 1998).

\section{Conclusions}

The focus on lesbian same-sex couples navigating health care settings relating to childbirth is an interesting case to consider as well because sexuality is salient and visible in a way that is not necessarily the case in other health care situations that LGBTQ people experience. Research indicates that LGBTQ people are not always out to their health care provider, citing the fear of discrimination (Eliason and Schope 2001). Despite their fear, in the case of lesbian same-sex couples having a child, the people interviewed for this study nonetheless wanted to be out and visible about their sexuality and family. For Erin and Phoebe, the process of having a child together actually facilitated their first time coming out to a stranger, in this case the OB/ GYN with whom they were working. Interviewees made it a point to research doctors and pediatricians who were LGBTQ-friendly, often relying on other LGBTQ friends and LGBTQ community organizations. Couples likewise discussed making an effort to include the nonbiological mother in all health care interactions and to talk with the staff at doctors' offices and hospitals about their status as a two-mom family. Thus similar to instances in other settings, same-sex couples with children may actually make LGBQ sexuality more visible in health care settings (Bernstein 2015). In fact it is precisely because of this visibility that couples described the fear they had. Although our chapter focuses only on lesbian same-sex couples having children, we argue that this case study provides insights into thinking about same-sex unions 
and health more broadly. Our work raises questions about what strategies couples might utilize to combat fear experienced in health-related contexts. Likewise, people's narratives highlight work that health care practitioners and health care offices can do to alleviate stigma and discrimination that LGBTQ people experience.

\section{References}

Baumle, Amanda, and D'Lane Compton. 2015. Legalizing LGBT Families: How the Law Shapes Parenthood. New York: New York University Press.

Bernstein, Mary. 2015. "Same-Sex Marriage and the Future of the LGBT Movement." Gender \& Society 29 (3): 321-337.

Dalton, Susan. 2001. "Protecting Our Parent-Child Relationships: Understanding the Strengths and Weaknesses of Second-Parent Adoption.” In Queer Families, Queer Politics: Challenging Culture and the State, edited by M. Bernstein and R. Reimann, 201-220. New York: Columbia University Press.

Eliason, Michele J., and Robert Schope. 2001. “Does ‘Don’t Ask Don't Tell' Apply to Health Care? Lesbian, Gay, and Bisexual People's Disclosure to Health Care Providers." Journal of the Gay and Lesbian Medical Association 5 (4): 125-134.

Emerson, Robert M., Rachel I. Fretz, and Linda L. Shaw. 1995. Writing Ethnographic Field Notes. Chicago: University of Chicago Press.

Erlanger, Howard. 2005. "Organizations, Institutions, and the Story of Shmuel: Reflections on the 4oth Anniversary of the Law and Society Association." Law and Society Review 39 (1): 1-10.

Ewick, Patricia and Susan S. Sibley. 1998. The Common Place of Law: Stories from Everyday Life. Chicago: University of Chicago Press.

Kazyak, Emily. 2015. “'The Law's the Law, Right?' Sexual Minority Mothers Navigating Legal Inequities and Inconsistencies." Sexuality Research and Social Policy 12 (3): 188-201.

Kazyak, Emily, Kelsy Burke, and Mathew Stange. 2018. "Logics of Freedom: Debating Religious Freedom Laws and Gay and Lesbian Rights.” Socius 4:1-18.

Melender, Hanna-Leena. 2002. "Experiences of Fears Associated with Pregnancy and Childbirth: A Study of 329 Pregnant Women.” Birth: Issues in Perinatal Care 29 (2): 101-111.

Miller, Susan. 2018. “3 Years after Same-Sex Marriage Ruling, Protections for LGBT Families Undermined.” USA Today. https://www.usatoday.com/story/news/nation/201B/06/04/ same-sex-marriage-ruling-undermined-gay-parents/650112002/

Obergefell v. Hodges, 135 S. Ct. 2071, 576 U.S., 1911. Ed. 2d 953 (2015).

Pavan v. Smith 137 S. Ct. 2075 (2017).

Richman, Kimberly D. 2009. Courting Change: Queer Parents, Judges, and the Transformation of American Family Law. New York: New York University Press. Simonds, Wendy, Barbara Katz Rothman, and Bari Meltzer Norman. 2007. Laboring On: Birth in Transition in the United States. New York: Routledge. 
Emily Kazyak is an associate professor of sociology and women's and gender studies at the University of Nebraska-Lincoln. Her research agenda focuses on the cultural and legal meanings of sexuality and how these meanings change, particularly with regard to increasing recognition of LGBTQ identities and families. Her recent research investigates American public opinion of religious freedom laws that reference LGBTQ people.

Emma Finken is a graduate student at the University of Nebraska-Lincoln. She is pursuing her master's degree in sociology and a graduate certificate in women's and gender studies. Her research interests include sexuality and social psychology. 